\title{
Time scale evaluation and the quantification of obliquity forcing
}

Christian Zeeden ${ }^{1,2,3}$, Stephen R. Meyers ${ }^{4}$, Frederik J. Hilgen ${ }^{2}$, Lucas J. Lourens ${ }^{2}$, Jacques Laskar $^{1}$

1) PSL, IMCCE, Observatoire de Paris, 77 Av. Denfert-Rochereau, 75014 Paris, France, christian.zeeden@obspm.fr

2) Faculty of Geosciences, University of Utrecht, Utrecht, Netherlands

3) LIAG, Leibniz Institute for Applied Geophysics, Stilleweg 2, 30655 Hannover, Germany

4) Department of Geoscience, University of Wisconsin-Madison, Madison, Wisconsin, USA

\begin{abstract}
The geologic time scale serves as an essential instrument for reconstructing Earth history. Astrochronology, linking regular sedimentary alternations to theoretical quasi-periodic astronomical rhythms, often provides the highest resolution age models for strata that underlie the time scale. Although various methods for testing astronomically-tuned time scales exist, they often present challenges, such as the problem of circularity. Here, we introduce an approach to extract a reliable obliquity envelope from astronomically tuned data, avoiding the effects of frequency modulations that can artificially introduce astronomical beats. This approach includes (1) the application of a broad obliquity filter followed by (2) a Hilbert transform and (3) a low-pass filter of the amplitude envelope to (4) test the significance of correlation between amplitude envelope and astronomical solution. These data amplitudes provide a robust means to evaluate the climate response to obliquity forcing and, more specifically, to test the significance of correlation with the theoretical astronomical solution, in a manner similar to the phase-randomized surrogate approach previously introduced for the
\end{abstract}


evaluation of precession tuning. Synthetic astronomical/ice-sheet models and numerous Quaternary climate proxy records - where obliquity can be a dominant component of astronomically driven climate variability - are used to demonstrate the feasibility of the proposed method and yield new insight into climate system evolution.

Keywords: Quaternary; Paleoclimatology; Data treatment, Data analysis; Obliquity; Tilt; Timescale testing; Astrochronology; Orbital climate forcing

\section{Introduction}

Astrochronology is an approach for developing high-resolution time scales, by linking cyclic variations observed in the stratigraphic record to climate variability induced by changes in Earth's orbit and rotational axis. The application of astrochronology as part of integrated stratigraphy has fundamentally advanced our understanding of the Earth's climate system. Approaches combining astronomical tuning and magnetostratigraphy were first developed for the late Quaternary (Hays et al., 1976), and then successively applied to older stratigraphic records (e.g. Shackleton et al., 1990; Hilgen, 1991; Hilgen et al., 1995; Westerhold et al., 2008; Westerhold and Röhl, 2009). A combination of radioisotopic dating and astrochronology has also proven powerful in constructing high-precision age models (e. g. Kuiper et al., 2008; Rivera et al., 2011; Meyers et al., 2012; De Vleeschouwer and Parnell, 2014; Sageman et al., 2014; Wotzlaw et al., 2014; Zeeden et al., 2014b; Hilgen et al., 2015), often in tandem with magneto- and biostratigraphy (e.g. Lourens et al., 1996b; Channell et al., 2010; Hüsing et al., 2010; Zeeden et al., 2013). The resulting geological time scales have an unprecedented accuracy, precision and resolution, as exemplified by the Astronomically Tuned Neogene Time Scales 2004 and 2012 (ATNTS; Gradstein et al., 2004, 2012; Lourens et al., 2004; Hilgen et al., 2012), among many others. 
The accuracy and precision of such astronomical time scales relies upon correct identification of the - sometimes noisy - astronomical signal embedded in the stratigraphic record (e.g. Meyers et al., 2008; Meyers, 2019). Testing geological datasets for astronomical forcing is not always straightforward, due to lack of independent time control and because formulation of the most appropriate null hypothesis can be challenging as a consequence of practical and conceptual differences between models and real geological data, including the presence of a range of noise sources and complex distortional relationships between time and stratigraphic depth (Ripepe and Fischer, 1991; Meyers et al., 2008; Meyers, 2012;

Proistosescu et al., 2012; Hilgen et al., 2015; Zeeden et al., 2015; Meyers, 2019). However, to address this problem, a number of statistical techniques have been proposed to evaluate a potential astronomical imprint within "un-tuned" depth scales and astronomically tuned time series (e.g. Meyers and Sageman, 2007; Hinnov, 2013, 2018; Hilgen et al., 2015; Meyers, 2015; Zeeden et al., 2015; Meyers, 2019).

A standard test for validating stand-alone astronomically-tuned time scales (those lacking detailed independent time control) against their astronomical-insolation tuning curves has been previously established for precession-dominated time series (Zeeden et al., 2015).

Shackleton et al. (1995) proposed that complex amplitude demodulation (or the Hilbert transform; see e.g. Bloomfield (2000)) is a powerful tool to test for the expected eccentricity amplitude modulation of the precession-related signal in paleoclimate records. They state that eccentricity amplitude modulation of precession is the "most important feature through which the orbital imprint may be unambiguously recognized in ancient geological records". This implies that cyclostratigraphers may use the hierarchical pattern of precession amplitudes, as modulated by eccentricity, to test the validity of proposed astrochronologies, either by eye or statistical methods (Shackleton et al., 1995; Meyers, 2015; Zeeden et al., 2015; Meyers, 2019). In this study, we build upon this philosophy by exploring the potential 
use of the $\sim 40$ kyr obliquity cycle, and its amplitude modulations by inclination associated with $\sim 175 \mathrm{kyr}$ and $\sim 1.2$ Myr cycles (Boulila et al., 2018; Laskar et al., 2004), as a means for astrochronologic testing in records that preserve obliquity forcing.

A number of approaches have been used to evaluate amplitude modulation of geological proxy data corresponding to astronomical patterns, including bandpass filter output (Tiedemann et al., 1994; Channell and Kleiven, 2000; Westerhold et al., 2005, 2008, 2014; Abels et al., 2010; Holbourn et al., 2013; Lauretano et al., 2015; Valero et al., 2014) and amplitude demodulation techniques (e.g. Shackleton et al., 1995; Shackleton and Crowhurst, 1997; Pälike et al., 2001, 2004, 2006; Westerhold et al., 2007; Wu et al., 2013, 2014, Zeeden et al., 2013, 2015). However, it is also known that eccentricity-like amplitude variations can be artificially introduced into paleoclimate data by tuning and data processing (Neeman, 1993; Shackleton et al., 1995; Huybers and Aharonson, 2010; Zeeden et al., 2015). In theory, bandpass filtering procedures can also generate artificial amplitude modulations that are similar in character to those of the theoretical obliquity modulation, complicating their use for astrochronologic testing.

To assess whether artificial amplitude variations also emerge in obliquity-tuned astrochronologies, we developed a new approach that circumvents the issue of introducing amplitude modulations during tuning and data processing of obliquity influenced records. This approach is similar, but in detail more sophisticated, than the procedure proposed for precession and its amplitude modulation by eccentricity (Zeeden et al., 2015). As will be demonstrated, even wide-band (conservative) obliquity filters do not fully remove artificial modulation effects (see Fig. 1, compare 1c, 1f). Therefore, we include a new simulation approach that fully counters frequency modulation effects. The proposed method involves seven steps: (1) the application of a wide-band obliquity filter to astronomically-tuned paleoclimate data, to deminish the potential for generation of strong artifical amplitude 
modulations that mimic obliquity amplitude, (2) application of a Hilbert Transform to calculate instantaneous amplitude, (3) lowpass filtering of the instantaneous amplitude to extract long-term obliquity modulations, (4) a new adaptive noise addition test, to identify the noise threshold at which residual artificial obliquity modulations are supressed, (5) addition of the threshold noise level to the astronomically-tuned paleoclimate data, (6) calculation of the Spearman Rank correlation coefficient (Spearman, 1904) between modulations observed in the tuned data and in the astronomical solution, (7) evaluation of the statistical significance of the results using phase-randomized (or auto-regressive; AR1) surrogates that preserve the power spectrum structure of the data, but have randomized amplitude modulations (Ebisuzaki, 1997).

Obliquity is known to be an inportant driver of paleoclimates of various regions and latitudes (e.g. Lee and Poulsen, 2008; Liu, 1992; von Suchodoletz et al., 2010; Zech et al., 2011; Bosmans et al., 2014; Laurin et al., 2015; Liu et al., 2015; Levy et al., 2019). Although classically prescribed as a high latitude signal, the gradient between low and high latitudes (Raymo and Nisancioglu, 2003) and the summer inter-tropical insolation gradient (SITIG) suggest the potential for a low latitude influence on obliquity forcing (Reichart, 1997; Leuschner and Sirocko, 2003; Bosmans et al., 2015). The contribution of obliquity to global climate change is not constant in time, and had an especially strong influence during the Early Quaternary (e.g. Ruddiman et al., 1989; Raymo and Nisancioglu, 2003). Thus, potential applications of the new method are wide ranging. As a test of the technique, we apply it to the (Imbrie and Imbrie, 1980) ice model, the LR04 benthic isotope stack (Lisiecki and Raymo, 2005), a dust deposition record from off NW Africa (Tiedemann et al., 1994) and a lake record from Siberia (Melles et al., 2012; Nowaczyk et al., 2013). In addition to providing a rigorous test of obliquity influence on these climate records, the new robust derived amplitude modulations yield a valuable tool for constraining the mechanisms of climate change. 


\section{Frequency and amplitude properties of obliquity}

The amplitude variations of obliquity are dissimilar to those associated with precession (Hinnov, 2000). Generally, obliquity periods are a combination of the precession constant, here denoted $\mathrm{k}$, and fundamental planetary frequencies associated with the so-called precession of the nodes, here denoted s,- ranging from s1 to s9, with the planets numbered from the Sun outwards. Importantly, drift in the main obliquity frequencies over time is expected to result from a change in the Earth/Moon system and the precession constant (e.g. Berger et al., 1989a, 1989b; Laskar et al., 1993, 2004; Hinnov, 2013; Meyers and Malinverno, 2018), but these changes do not directly influence obliquity amplitude variations because the associated precession constant terms cancel each other out with only the orbital inclination component remaining. Consequently, obliquity amplitudes are reliable back in time as far as eccentricity (ca. $50 \mathrm{Ma}$, see Laskar et al., 2011; Westerhold et al., 2012), while its phase is less well constrained beyond $10 \mathrm{Ma}$ (Zeeden et al., 2014a). Therefore obliquity amplitudes are valuable tuning targets in e.g. the Eocene (Boulila et al., 2018).

\subsection{Obliquity frequencies}

Several obliquity frequency components occur with periods around 40-41 kyr, collectively resulting in the prominent $\sim 40 \mathrm{kyr}$ obliquity cycle. In particular, the $\mathrm{k}+\mathrm{s} 3, \mathrm{k}+\mathrm{s} 4$ components and the $\mathrm{k}+\mathrm{s} 3+\mathrm{g} 4-\mathrm{g} 3$ term are dominant, but more components are found in this frequency band (Laskar, 1999). Further, obliquity comprises components with periods around 29 and 54 kyr, above all caused by $\mathrm{k}+\mathrm{s} 1$ and $\mathrm{k}+\mathrm{s} 6$, respectively. The obliquity frequencies (black) compared to amplitude frequencies (red) are shown in Figure 1g.

\subsection{Obliquity amplitude modulations}


Obliquity amplitude variations are the result of individual obliquity frequencies and their interference. The amplitude variations have dominant periods of $\sim 1.2$ and $\sim 2.5 \mathrm{Myr}$, and of $\sim 175$ kyr, with other weak components present (see Fig. 1g, red, and also Hinnov, 2000, 2013). The 1.2 Myr cycle is already clearly seen in an obliquity time series (Fig. 1a), and results from the two strongest obliquity components $(k+s 3)$ and $(k+s 4)$, which produce the amplitude modulation (s3 - s4, related to Mars and Earth) through interference. Filtering of these components (Fig. 1b, h) results in a clear 1.2 Myr cycle, while also a lower frequency cycle of about twice the period emerges. This $\sim 2.5 \mathrm{Myr}$ cycle results from the combination of $\mathrm{k}+\mathrm{s} 4$ and $\mathrm{k}+\mathrm{s} 3+\mathrm{g} 4-\mathrm{g} 3$. A shorter obliquity amplitude cycle with a period around $175 \mathrm{kyr}$ (Fig. $1 \mathrm{~g}, \mathrm{i})$ originates from the interaction of the $\mathrm{k}+\mathrm{s} 6(\sim 54 \mathrm{kyr})$ component with components around 41 kyr duration, dominated by the interaction of Earth and Saturn (Boulila et al., 2018; Hinnov, 2000). A relatively weak 100 kyr amplitude cycle (Fig. 1g, i) results from combining k+s1 (29 kyr) with components around $41 \mathrm{kyr}$.

Both narrow- and wide-band obliquity filters mimic obliquity and its frequency components, where narrow-band filters mainly represent the $\sim 1.2$ Ma component (compare Fig. 1b, c, h, i).

\subsection{Obliquity frequency- versus amplitude modulations}

As is the case for precession (Zeeden et al. 2015), obliquity has the property of being both amplitude- and frequency modulated (Hinnov, 2000), the latter of which is the source of spurious amplitude modulations that can be imposed during astronomical tuning and data processing (see Huybers and Aharonson, 2010; Zeeden et al., 2015). Amplitude and frequency are related (see Supplementary Fig. 1; and also (Hinnov, 2000)), and the obliquity frequency deviates most from its mean value during low obliquity amplitude intervals (see Figs. 1, 2 and Supplementary Fig. 1). However, it is also important to note that for the $\sim 1.2$ Myr component, the amplitude modulation is much stronger than the frequency modulation, when compared to the other modulating terms (Hinnov, 2000). To evaluate the effect of these 
frequency modulations on astrochronologic testing, we present a synthetic test series comprised of amplitude demodulated obliquity (Fig. 1d), spanning the last $6 \mathrm{Ma}$ (using the ‘astrochron' R package (Meyers, 2014; R Core Team, 2017); see supplementary R code for model generation). This synthetic series is analagous to a stratigraphic record that has been tuned to the theoretical obliquity solution (Laskar et al., 2004), but lacks expected amplitude modulation (it plays the same role as axial precession does in the study by Zeeden et al., 2015).

Relatively narrow-band filtering of the demodulated synthetic test series (Fig. 1e, 1k), here exemplified as a 37-43 kyr Taner bandpass filter (Taner, 1992), expresses amplitude properties similar to the original $\sim 1.2 \mathrm{Myr}$ modulation of obliquity (Fig. 1b, 1h). In contrast, using a wider bandpass filter (here exemplified as a 26-67 kyr Taner bandpass filter; the cutoff at $26 \mathrm{kyr}$ is used to avoid precession components) shows deminished amplitude modulation (see Figs. 1f, 11) relative to the narrow filter (Fig. 1e, 1k). Weak correlative features during extreme minima in the obliquity amplitude (Fig. 1f, especially around 3.2 and 4 Ma; Spearman Rank correlation between obliquity amplitude and demodulate obliquity amplitude is 0.07 , compare Fig. 1a, 1f) persist, demonstrating that wide filters cannot circumvent possible modulations introduced by the tuning process. Problematically, substantial correlation of demodulated obliquity filter amplitudes and real obliquity amplitudes persists when applying wide-band filters, and correlations are particularly strong in obliquity amplitude minima, affecting filters differently in different time intervals (Figs. 1, 2). Thus, amplitude modulation expressed in real paleoclimate data may either represent the true amplitude modulation, or may be artificially generated during the tuning process by interactions between the bandpass filter and the frequency modulation imposed during tuning.

\section{Validating obliquity-dominated astronomically tuned datasets}


Similar to precession, one means to overcome the problem of artificially imposing obliquity amplitude modulation is via a minimal tuning approach (Lourens and Hilgen, 1997; Zeeden et al., 2015). However, minimal tuning approaches for obliquity may be challenging to impossible in practice, because tuning to the long-term obliquity amplitude variation $(\sim 1.2$ Myr) is not very helpful in records with sedimentation rates that vary on shorter time-scales. Additionally, the exact position of these long term minima and maxima may be difficult to pinpoint in geological datasets. However, tuning using one tie point per $\sim 175 \mathrm{kyr}$ (s3-s6) obliquity amplitude variation cycle may be feasible in cases where this modulation is clearly visible in data (Boulila et al., 2018).

In contrast to precession (Zeeden et al., 2015), circumventing the potential problem of introducing amplitude modulations during comprehensive (cycle-by-cylce) tuning, by specific filter designs, is not fully possible for obliquity (Figs. 1 and 2). This problem is likely to persist for time series tuned to obliquity or target curves containing obliquity, such as e.g. the $65^{\circ} \mathrm{N}$ insolation or p-0.5t (see e.g. Lourens et al., 1996a, 2001; Abels et al., 2009). However, of critical importance, artificial amplitude modulations are weak (see Fig. 1d and f) compared to true obliquity amplitude modulation (Fig 1a and c). For the test data sets in Fig. 1, the standard deviation of the low-pass filtered obliquity amplitude is much higher than that resulting from the demodulated obliquity case (compare Fig. 1a, 1d). We take advantage of this key attribute in our astrochronologic testing algorithm.

We implement a test similar to 'testPrecession' (Meyers, 2014; Zeeden et al., 2015), but modify the algorithm to include a contribution of noise to the dataset, which counters the expression of artificial modulations, proving a reliable test. There are several key issues at hand. First, the noise that is added should express the same general broadband structure as the data. Second, we want to add enough noise to counter the expresion of artificial modulations, but not too much to destroy true modulations; the relative amount of noise that must be added 
to a given record will be specific to the time interval under investigation (Fig. 2). To address the first concern, noise is generated using an AR1 model, with the same lag-1 autocorrelation coefficient as the real geologic data. Regarding the second concern, the appropriate level of noise to add is determined by starting with a demodulated test series from the same time interval (generated from Laskar et al., 2004), to which increasing levels of noise are added until the correlation between the synthetic amplitudes (demodulated obliquity plus noise) and true obliquity are $\leq 0$. Once the appropriate level of noise is identified, it is added to the geologic data. This noise addition process will be unique to each dataset (adaptive), because the amount of noise required depends on the length, resolution and autocorrelation of a dataset and its age. For filtering obliquity, a relatively wide taner filter is used from 0.015 [1/kyr] to $0.038[1 / \mathrm{kyr}]$ with a roll-off rate of $10^{20}$, see also Figures $1 \mathrm{i}$ and 11 for a visualisation of the filter properties. Obliquity amplitudes are low-pass filtered at 0.0015 with a roll-off rate of $10^{4}$ (deviating from the standard setting of the testTilt function). It is important to note that the specific characteristics of the wide-band obliquity and lowpass filters used here have been chosen to faciliate the detection of the $\sim 1.2$ Myr obliquity amplitude modulations, but other possible filter designs are possible. In particular, using different lowpass filters to include the 175 kyr obliquity amplitude modulation may be useful in some cases.

To provide a quantitative measure of fit, the correlation between theoretical obliquity amplitude and the filtered (data) instantaneous amplitude is determined using the Spearman Rank correlation coefficient (Spearman, 1904), which allows for a degree of non-linearity between forcing and response. The obliquity reference series (Laskar et al., 2004) is processed using an identical approach as the data, to generate the theoretical obliquity amplitude target used for comparison. Evaluation of the statistical significance of correlation between theoretical obliquity modulations and the lowpass filtered obliquity amplitude (including data + noise) is conducted via Monte Carlo simulation of phase-randomized surrogate datasets, as 
implemented in the R ‘astrochron’ package (Ebisuzaki, 1997; Meyers, 2014; R Core Team, 2017). Each simulation uses surrogates that have identical power spectra to the the paleoclimate data and the theoretical obliquity, but with randomized phase. Comparison of the observed data correlation with those from Monte Carlo simulations of surrogates allows a rigorous evaluation of the null hypothesis (no correlation between obliquity target and observed modulations). In cases where no surrogate can reach a better correlation than the tuned record, the $\mathrm{p}$-value is given as $1 / \mathrm{N} * 10$, where $\mathrm{N}$ represents the number of simulations (Meyers, 2014; Zeeden et al., 2015). The full algorithm is outlined in Figure 3, illustrating results for a tilt series (left; correlation 0.99 and p-value $<0.01$ based on 5000 surrogate simulations), for an amplitude-demodulated obliquity signal (middle; correlation 0.54 , p-value 0.8), and for an amplitude-demodulated obliquity plus AR1 noise series (right; correlation 0.05; also negative after noise addition; again no $\mathrm{p}$-value is useful because of negative correlation when noise is included to remove frequency modulation effects). This demonstrates the suitability of the method to circumvent frequency modulation and tuning effects. Complementary to this study, a function 'testTilt' that conducts the full analysis has been developed for “astrochron: An R Package for Astrochronology” (Meyers, 2014).

\section{Testing time series}

To determine if obliquity amplitude modulations are truly present in datasets we use the filtering procedure as outlined above. This procedure tests if obliquity amplitude variations may derive from frequency modulation introduced by the astronomical tuning and data processing procedure, or whether they are an inherent property of the datasets. As test cases for the new validation approach using obliquity, we investigate the (Imbrie and Imbrie, 1980) ice model, as parameterized as by (Lisiecki and Raymo, 2005), followed by the LR04 benthic isotope stack (Lisiecki and Raymo, 2005). We then investigate relatively long and 
continuous Quaternary datasets, specifically the ODP Site 659 dust record (Tiedemann et al., 1994) and the magnetic susceptibility record from Arctic Lake El'Gygytgyn (Melles et al., 2012; Nowaczyk et al., 2013). Tests with these three datasets use a cutoff frequency of 1/500 [1/kyr] to focus on the low-frequency components of the obliquity amplitude; to compensate for secular drifts, the obliquity envelopes (not original data) of the datasets were linearly detrended before comparison with theoretical obliquity. The cut off frequency deviates from standard setting of the testTilt function, and this choice made deliberately here to obtain a useful and comparable outcome and basis for interpretation (various settings were tested). Following this, we use the new reconstructed obliquity amplitudes to evaluate mechanisms of climate change during the Pleistocene. Table 1 summarizes properties of the described case studies. Please note that procedures include simulation, and therefore results from different runs will not be identical. Here we used 10,000 simulations to obtain robust p-values, where we consider p-values below 0.05 significant. The choice of which p-value can be considered significant is subject to debate, and other choices may be made but should be reported.

\subsection{Testing the Imbrie \& Imbrie (1980) ice model}

The (Imbrie and Imbrie, 1980) ice model, which represents a nonlinear response to northern hemisphere insolation forcing, was used as a tuning target for the LR04 benthic $\delta^{18} \mathrm{O}$ stack, using the specific parametrization described in (Lisiecki and Raymo, 2005). This ice model, forced by $65^{\circ}$ northern latitude June 21 insolation, results in an obliquity amplitude envelope significantly correlated to obliquity (p-value $<0.001$; Fig 4). It should be noted here that the amplitude variation of the Imbrie ice model decreases over the last 5 million years, while the amplitudes of most proxy data, including the LR04 stack, show increasing amplitudes over this time frame (Fig. 4). As the Imbrie ice model uses insolation including obliquity as input, orbitally-driven obliquity amplitudes may be expected.

\subsection{Testing the $\mathrm{LRO4} \delta^{18} \mathrm{O}$ benthic isotope stack}


A benthic foraminifer oxygen isotope stack for the last 5.3 Ma was published (LR04; Lisiecki and Raymo, 2005), which serves as a standard reference dataset for numerous studies. The LR04 stack is often used as correlation target for time scale construction or consistency testing (e.g. Necula and Panaiotu, 2008 ; Buggle et al., 2009; Marković et al., 2012; Basarin et al., 2014; Kaboth et al., 2016). The LR04 stack was correlated to the Imbrie and Imbrie (1980) ice model, which uses northern hemisphere summer insolation as model input, and therefore exhibits patterns of precession and obliquity, as well as non-linear features. As a secondary constraint, obliquity was used to fine-tune portions of the LR04 stack (Lisiecki and Raymo, 2005).

The LR04 stack has a trend towards higher variability and heavier $\delta^{18} \mathrm{O}$ values towards recent (Fig. 5). Testing this dataset results in a significant (p-value is 0.015 ) correlation between the astronomical obliquity amplitude and the obliquity amplitude as reconstructed from this dataset, when focusing on the $\sim 1.2 \mathrm{Ma}$ long-term component. We choose to linearly detrend the data amplitudes before comparison, because the trend toward higher $\delta^{18} \mathrm{O}$ variability and heavier values is unique to global climate evolution, and not a feature of the predicted astronomical variations.

\subsection{Testing the Lake El'Gygytgyn time scale for the last $2.8 \mathrm{Ma}$}

An exceptional lacustrine record from Lake El'Gygytgyn in northeast Russia was recovered in the frame of the International Continental Drilling Project (Melles et al., 2012, 2011). The time scale of this record is based on an integrated approach using information from magnetostratigraphy, correlation to the LR04 stack and astronomical tuning (Nowaczyk et al., 2013). Investigating the obliquity component of the magnetic susceptibility record (which represents a proxy for lake oxygenation, as during anoxic phases magnetic minerals were dissolved; Melles et al., 2012; Nowaczyk et al., 2013; Fig. 5) indicates a p-value of $<0.049$ for the correlation between the dataset- and astronomical obliquity amplitudes, 
significant at $>95 \%$ confidence. All three long-term maxima in the obliquity amplitude envelope are seen as such in the El'Gygytgyn dataset. In addition, increased obliquity amplitude is seen at $\sim 700-800 \mathrm{ka}$ and $\sim 1900 \mathrm{ka}$, suggesting changes in climate system sensitivity to obliquity. Such an interpretation needs to be taken with care, because other influences may also play a role (se chapter 5.1.).

\subsection{Testing a Quaternary and Pliocene dust record from offshore NW Africa}

High-resolution records of benthic foraminifera oxygen isotopes and dust flux from ODP Site 659 in the north-eastern subtropical Atlantic have been tuned to the Ber90 astronomical solution (Berger and Loutre, 1991) for the last 5 Ma with an average tie point spacing of $24 \mathrm{kyr}$ (Tiedemann et al., 1994). According to Tiedemann et al. (1994), the good fit between the amplitude modulation of the filtered precession component in the dust flux record and eccentricity as well as that between the long-term (i.e. 1.2 Myr) obliquity amplitude modulation in the benthic oxygen isotope record with that of the astronomical obliquity cycle provide robust arguments in favor of their tuned time scale. Note that Clemens (1999) discuss a tuning option deviating by one 41 kyr obliquity cycle for the lower Pliocene part of the record due to uncertainties in the Ber90 (Berger and Loutre, 1991) solution. To evaluate the time scale and astronomical interpretations of Tiedemann et al. (1994), we applied the same methods as described above to test whether the astronomically tuned records of ODP 659 reveal true obliquity amplitude or artificial frequency modulated amplitudes (Fig. 6); as reference we used the La2004 (Laskar et al., 2004) solution, where the original study used the (Berger and Loutre, 1991) solution. These solutions are almost identical over the last $5 \mathrm{Ma}$ (Supplementary Figure 3). It should be reminded that the orbital part of the solution published in (Berger and Loutre, 1991) is the one originally obtained by (Laskar, 1988). It is thus expected that the envelope of obliquity of is the same as in Laskar et al. (1993), and very similar to Laskar et al. (2004) over the last 5 Ma. 
Figure 7 shows the comparison between theoretical obliquity amplitude and data tilt amplitude from the dust flux record using the tuning by Tiedemann et al. (1994). Obliquity amplitudes from these two datasets are in good agreement, with a Spearman Rank correlation of 0.67 , and a p-value of 0.0041 ; agreement is especially good in the time interval between ca. 3 and 1 Ma. In general, the obliquity amplitude of the dust flux record (Tiedemann et al., 1994) confirms the proposed astrochronology on a $~ 1.2$ Myr scale. Investigation of the precession amplitude (Fig.7 d, e) yields higher resolution confirmation, and indicates a superior fit of the older portion of the record (Spearman Rank correlation of 0.41), with a pvalue of $<0.001$ for the entire interval. We conclude that frequency modulations introduced by the tuning process play a minor role for time scale evaluation in this example, and that real data amplitudes dominate the record.

\section{Discussion}

\subsection{Time scale validation}

In prior studies, precession and eccentricity frequency properties (Hinnov and Park, 1998; Rial, 1999; Huybers and Aharonson, 2010) and amplitude modulations (e.g. Wu et al., 2014; Meyers, 2015; Zeeden et al., 2015) have been used for time scale evaluation and paleoclimatic investigations, while obliquity amplitude modulations are less commonly investigated (e.g. Liu, 1992, 1995, 1998; Mélice et al., 2001; Meyers, 2019). Here a validation approach for obliquity dominated time series is presented allowing for robust evaluation of the correlation between tuned data amplitude envelopes and those of the astronomical obliquity target. This approach is similar to the precession/eccentricity case (Zeeden et al., 2015), but requires additional care because frequency modulations cannot fully be avoided by specific filter properties. The method is tested using two model series (obliquity, Fig. 3; the Imbrie ice model, Fig. 5), and three proxy data series. It is critical to note that in our 
assessment of data sets, the specific tuning options investigated may not be the only ones that would result in a statistically significant relationship. A good fit of the data amplitude envelope and $\sim 1.2 \mathrm{Myr}$ obliquity amplitudes probably allows for a shift in tuning by several individual obliquity cycles. Misfits between data and tuning target may be the result of various issues. Further, the choice of cut-off frequencies for investigating long-term obliquity variations influences results.

In the late Quaternary, and specifically the last $\sim 1.4 \mathrm{Ma}$, obliquity is not a dominant property of most datasets (e.g. Lisiecki and Raymo, 2005), and amplitude investigations may give a less good fit than for the time interval from 3-1.4 Ma. Shackleton et al. (1995) noted that amplitude demodulation is not always applicable to evaluate paleoclimate time series, but requires data showing a strong/dominant signal in the frequency to be analyzed. As obliquity is not always a dominant astronomical influence on paleoclimate, the approach described may not be as widely applicable as a similar method for testing precession dominated time scales (Zeeden et al., 2015). When both strong precession and obliquity are present in a paleoclimate record, however, demodulation results from both terms provide the opportunity for crossvalidation, as demonstrated in our analysis of data from ODP Site 659 (Fig. 7).

Here, we present several cases where the obliquity amplitude as observed in geological data is linked to the initial orbital forcing, giving confidence to astronomical time scales. In cases where no statistically significant link and correlation between data and template is obtained, an inadequate time scale represents only one out of several possible interpretations. As discussed here, also a change in the paleoclimatic feedback as recorded by proxy data may result in such an unfortunate outcome. Where the overall fit between obliquity as reconstructed from data is only convincing in certain intervals, time scales may require adjustment, or the obliquity imprint may be stronger and/or different in these intervals. Generally, time scales based on insignificant correlation to orbital templates should be treated 
with adequate care, and information from integrated stratigraphy will be necessary for further evaluations.

\subsection{Investigating Earth's climate response to obliquity forcing}

The 'testTilt' method extracts obliquity amplitudes with minimal bias from frequency modulations, and can thus be applied for purposes other than time-scale testing. This specifically includes the investigation of proxy data from the Cenozoic and beyond, where 'testTilt' extracts obliquity amplitude, and provides a statistical comparison to the La2004 solution (Laskar et al., 2004). All data sets investigated here (but not the Imbrie and Imbrie (1980) model) show a rather high obliquity amplitude around ca. 750 ka (Fig. 8), during the Mid-Pleistocene transition (e.g. Mudelsee and Stattegger, 1997). This has been observed before in the detrended power of obliquity (Lisiecki and Raymo, 2007) and in evolutive harmonic analyses (Meyers and Hinnov, 2010). Enhanced obliquity is seen in paleoclimate records from the north Atlantic (e.g. Mudelsee and Stattegger, 1997; Raymo et al., 2004) and South Atlantic IRD (Becquey and Gersonde, 2002), implying that Earth's high latitude climate system had an amplified obliquity feedback in this specific time interval. This motivates future work to evaluate specific mechanisms for obliquity amplification.

The long-term influence of obliquity on paleoclimate can be assessed using the proposed testTilt method. With an ever-increasing number of high-resolution records becoming available, this method is likely to become useful beyond the Quaternary. A similar approach may be used to detect obliquity amplitude variations which can be indicative of chaotic solar system behavior (e.g. Ma et al., 2017).

Nonlinearities such as skewed and rectified records, and age model uncertainties, may impose complications when attempting to extract obliquity and its amplitudes from geological data. However, the wideband filters applied here may be expected to counter effects of 
skewness and age model uncertainties in at least some cases. This assertion is supported by our evaluation of a nonlinear ice sheet model and several proxy data sets. In cases where obliquity is a minor contributor to the overall data variability, it may only be clearly expressed for time intervals when other (precession, eccentricity) components have rather low variability (e.g. Lourens et al., 2010; Zeeden et al., 2013). This may complicate the extraction of true obliquity amplitudes, as these would coincide with eccentricity minima rather than obliquity amplitude maxima. Generally, amplitude investigations need to be treated with caution when the investigated component is not dominant (Shackleton et al., 1995).

\section{Conclusions}

Time scales tuned to obliquity can be influenced by the tuning process and introduce artificial amplitude modulations (linked to imposed frequency modulation), as the variations in Earth's axial tilt exhibit both frequency- and amplitude variations. This study develops methodologies to circumvent the introduction of artificial amplitude modulations by astronomical tuning and data processing, allowing the use of these amplitude variations for robust interpretation. Similar to methods developed for precession, we introduce a quantitative statistical technique that employs the Hilbert Transform, a series of filters to extract true obliquity amplitude modulations from paleoclimate proxy data, and an adaptive noise addition step for reliable significance testing, where necessary. The method includes simulations to evaluate the null hypothesis of no correlation between observed data modulations and the theoretical obliquity target series. Both the $\sim 1.2 \mathrm{Myr}$ and also the $\sim 175$ kyr obliquity amplitude components can be seen in Quaternary paleoclimate proxy data and may be used for time scale evaluation and also paleoclimate research. We suggest to generally

use wideband filters when amplitudes are to be investigated, which are less affected by frequency modulation effects than narrowband filters, facilitating 'robust amplitudes'. We 
consistently find elevated obliquity amplitudes around $750 \mathrm{ka}$ in three geological datasets from the northern hemisphere, which may be related to the Mid-Pleistocene transition.

\section{Acknowledgements:}

C.Z. is funded by a PSL fellowship. The research leading to these results has received funding from the [European Community's] Seventh Framework Programme ([FP7/2007-2013] under grant agreement $\mathrm{n}^{\circ}$ [215458], and was also supported by the U.S. National Science Foundation (award EAR-1151438 to SRM). An ESF grant and support from IMMCE, Observatoire de Paris, facilitated personal communication. All data used here is available in the Pangaea database and from other web resources; the $\mathrm{R}$ code for generating figures is appended. The Imbrie \& Imbrie (1980) ice model was constructed using the 'imbrie' function of the 'astrochron' R package, and the 'testTilt' function for 'astrochron' has been created to allow rapid execution and reproduction of results. These two functions will be made available in the 'astrochron' $\mathrm{R}$ package parallel to publication of this manuscript. 


\section{Bibliography}

Abels, H.A., Abdul Aziz, H., Calvo, J.P., Tuenter, E., 2009. Shallow lacustrine carbonate microfacies document orbitally paced lake-level history in the Miocene Teruel Basin (NorthEast Spain). Sedimentology 56, 399-419. https://doi.org/10.1111/j.1365-3091.2008.00976.x

Abels, H.A., Aziz, H.A., Krijgsman, W., Smeets, S.J.B., Hilgen, F.J., 2010. Long-period eccentricity control on sedimentary sequences in the continental Madrid Basin (middle Miocene, Spain). Earth Planet. Sci. Lett. 289, 220-231.

https://doi.org/10.1016/j.epsl.2009.11.011

Basarin, B., Buggle, B., Hambach, U., Marković, S.B., Dhand, K.O., Kovačević, A., Stevens, T., Guo, Z., Lukić, T., 2014. Time-scale and astronomical forcing of Serbian loess-paleosol sequences. Glob. Planet. Change 122, 89-106.

https://doi.org/10.1016/j.gloplacha.2014.08.007

Becquey, S., Gersonde, R., 2002. Past hydrographic and climatic changes in the Subantarctic Zone of the South Atlantic - The Pleistocene record from ODP Site 1090. Palaeogeogr.

Palaeoclimatol. Palaeoecol. 182, 221-239. https://doi.org/10.1016/S0031-0182(01)00497-7

Berger, A., Loutre, M. f., Dehant, V., 1989a. Astronomical frequencies for pre-Quaternary palaeoclimate studies. Terra Nova 1, 474-479. https://doi.org/10.1111/j.13653121.1989.tb00413.x

Berger, A., Loutre, M.F., 1991. Insolation values for the climate of the last 10 million years. Quat. Sci. Rev. 10, 297-317. https://doi.org/10.1016/0277-3791(91)90033-Q

Berger, A., Loutre, M.F., Dehant, V., 1989b. Pre-Quaternary Milankovitch frequencies. Nature 342, 133-133. https://doi.org/10.1038/342133b0

Bloomfield, P., 2000. Fourier Analysis of Time Series. New York: John Wiley.

Bosmans, J.H.C., Drijfhout, S.S., Tuenter, E., Hilgen, F.J., Lourens, L.J., 2014. Response of the North African summer monsoon to precession and obliquity forcings in the EC-Earth GCM. Clim. Dyn. 44, 279-297. https://doi.org/10.1007/s00382-014-2260-z

Bosmans, J.H.C., Hilgen, F.J., Tuenter, E., Lourens, L.J., 2015. Obliquity forcing of lowlatitude climate. Clim Past 11, 1335-1346. https://doi.org/10.5194/cp-11-1335-2015

Boulila, S., Vahlenkamp, M., De Vleeschouwer, D., Laskar, J., Yamamoto, Y., Pälike, H., Kirtland Turner, S., Sexton, P.F., Westerhold, T., Röhl, U., 2018. Towards a robust and consistent middle Eocene astronomical timescale. Earth Planet. Sci. Lett. 486, 94-107. https://doi.org/10.1016/j.eps1.2018.01.003

Buggle, B., Hambach, U., Glaser, B., Gerasimenko, N., Marković, S.B., Glaser, I., Zöller, L., 2009. Stratigraphy, and spatial and temporal paleoclimatic trends in Southeastern/Eastern European loess-paleosol sequences. Quat. Int., Lower Latitudes Loess-Dust Transport Past and Present 196, 86-106. https://doi.org/10.1016/j.quaint.2008.07.013 
Channell, J.E.T., Hodell, D.A., Singer, B.S., Xuan, C., 2010. Reconciling astrochronological and 40Ar/39Ar ages for the Matuyama-Brunhes boundary and late Matuyama Chron. Geochem. Geophys. Geosystems 11, n/a-n/a. https://doi.org/10.1029/2010GC003203

Channell, J.E.T., Kleiven, H.F., 2000. Geomagnetic palaeointensities and astrochronological ages for the Matuyama-Brunhes boundary and the boundaries of the Jaramillo Subchron: palaeomagnetic and oxygen isotope records from ODP Site 983. Philos. Trans. R. Soc. Lond. Math. Phys. Eng. Sci. 358, 1027-1047. https://doi.org/10.1098/rsta.2000.0572

Clemens, S.C., 1999. An astronomical tuning strategy for Pliocene sections: implications for global-scale correlation and phase relationships. Philos. Trans. R. Soc. Lond. Math. Phys. Eng. Sci. 357, 1949-1973. https://doi.org/10.1098/rsta.1999.0409

De Vleeschouwer, D., Parnell, A.C., 2014. Reducing time-scale uncertainty for the Devonian by integrating astrochronology and Bayesian statistics. Geology 42, 491-494.

https://doi.org/10.1130/G35618.1

Ebisuzaki, W., 1997. A Method to Estimate the Statistical Significance of a Correlation When the Data Are Serially Correlated. J. Clim. 10, 2147-2153. https://doi.org/10.1175/15200442(1997)010<2147:AMTETS>2.0.CO;2

Gradstein, F., Ogg, J., Schmitz, M., Ogg, G., 2012. The Geologic Time Scale 2012. Fac. Authored Books.

Gradstein, F.M., Ogg, J.G., Smith, A.G., 2004. A Geologic Time Scale 2004. Cambridge University Press.

Hays, J.D., Imbrie, J., Shackleton, N.J., 1976. Variations in the Earth's Orbit: Pacemaker of the Ice Ages. Science 194, 1121-1132. https://doi.org/10.1126/science.194.4270.1121

Hilgen, F.J., 1991. Astronomical calibration of Gauss to Matuyama sapropels in the Mediterranean and implication for the Geomagnetic Polarity Time Scale. Earth Planet. Sci. Lett. 104, 226-244. https://doi.org/10.1016/0012-821X(91)90206-W

Hilgen, F.J., Hinnov, L.A., Aziz, H.A., Abels, H.A., Batenburg, S., Bosmans, J.H.C., Boer, B. de, Hüsing, S.K., Kuiper, K.F., Lourens, L.J., Rivera, T., Tuenter, E., Wal, R.S.W.V. de, Wotzlaw, J.-F., Zeeden, C., 2015. Stratigraphic continuity and fragmentary sedimentation: the success of cyclostratigraphy as part of integrated stratigraphy. Geol. Soc. Lond. Spec. Publ. 404, 157-197. https://doi.org/10.1144/SP404.12

Hilgen, F.J., Krijgsman, W., Langereis, C.G., Lourens, L.J., Santarelli, A., Zachariasse, W.J., 1995. Extending the astronomical (polarity) time scale into the Miocene. Earth Planet. Sci. Lett. 136, 495-510. https://doi.org/10.1016/0012-821X(95)00207-S

Hilgen, F.J., Lourens, L.J., Van Dam, J.A., others, 2012. The Neogene Period.

Hinnov, L.A., 2018. Cyclostratigraphy and Astrochronology in 2018, in: Stratigraphy and Time Scale, Volume Three. Academic Press. 
Hinnov, L.A., 2013. Cyclostratigraphy and its revolutionizing applications in the earth and planetary sciences. Geol. Soc. Am. Bull. 125, 1703-1734. https://doi.org/10.1130/B30934.1

Hinnov, L.A., 2000. New Perspectives on Orbitally Forced Stratigraphy. Annu. Rev. Earth Planet. Sci. 28, 419-475. https://doi.org/10.1146/annurev.earth.28.1.419

Hinnov, L.A., Park, J., 1998. Detection of astronomical cycles in the stratigraphic record by frequency modulation (FM) analysis. J. Sediment. Res. 68, 524-539.

https://doi.org/10.2110/jsr.68.524

Holbourn, A., Kuhnt, W., Clemens, S., Prell, W., Andersen, N., 2013. Middle to late Miocene stepwise climate cooling: Evidence from a high-resolution deep water isotope curve spanning 8 million years. Paleoceanography 28, 688-699. https://doi.org/10.1002/2013PA002538

Hüsing, S.K., Cascella, A., Hilgen, F.J., Krijgsman, W., Kuiper, K.F., Turco, E., Wilson, D., 2010. Astrochronology of the Mediterranean Langhian between 15.29 and 14.17 Ma. Earth Planet. Sci. Lett. 290, 254-269. https://doi.org/10.1016/j.epsl.2009.12.002

Huybers, P., Aharonson, O., 2010. Orbital tuning, eccentricity, and the frequency modulation of climatic precession. Paleoceanography 25. https://doi.org/10.1029/2010PA001952

Imbrie, J., Imbrie, J.Z., 1980. Modeling the Climatic Response to Orbital Variations. Science 207, 943-953. https://doi.org/10.1126/science.207.4434.943

Kaboth, S., Bahr, A., Reichart, G.-J., Jacobs, B., Lourens, L.J., 2016. New insights into upper MOW variability over the last 150kyr from IODP 339 Site U1386 in the Gulf of Cadiz. Mar. Geol., STRATIGRAPHIC AND SEDIMENTARY SIGNIFICANCE OF THE MEDITERRANEAN OUTFLOW WATER AND ITS CONCEPTUAL IMPLICATIONS 377, 136-145. https://doi.org/10.1016/j.margeo.2015.08.014

Kuiper, K.F., Deino, A., Hilgen, F.J., Krijgsman, W., Renne, P.R., Wijbrans, J.R., 2008. Synchronizing Rock Clocks of Earth History. Science 320, 500-504.

https://doi.org/10.1126/science.1154339

Laskar, J., 1999. The limits of Earth orbital calculations for geological time-scale use. Philos. Trans. R. Soc. Lond. Ser. Math. Phys. Eng. Sci. 357, 1735-1759.

Laskar, J., 1988. Secular evolution of the solar system over 10 million years. Astron. Astrophys. 198, 341-362.

Laskar, J., Fienga, A., Gastineau, M., Manche, H., 2011. La2010: a new orbital solution for the long-term motion of the Earth. Astron. Astrophys. 532, A89.

https://doi.org/10.1051/0004-6361/201116836

Laskar, J., Joutel, F., Boudin, F., 1993. Orbital, precessional, and insolation quantities for the Earth from-20 Myr to+ 10 Myr. Astron. Astrophys. 270, 522-533. 
Laskar, J., Robutel, P., Joutel, F., Gastineau, M., Correia, A.C.M., Levrard, B., 2004. A longterm numerical solution for the insolation quantities of the Earth. Astron. Astrophys. 428, 261-285.

Lauretano, V., Littler, K., Polling, M., Zachos, J.C., Lourens, L.J., 2015. Frequency, magnitude and character of hyperthermal events at the onset of the Early Eocene Climatic Optimum. Clim Past 11, 1313-1324. https://doi.org/10.5194/cp-11-1313-2015

Laurin, J., Meyers, S.R., Uličný, D., Jarvis, I., Sageman, B.B., 2015. Axial obliquity control on the greenhouse carbon budget through middle- to high-latitude reservoirs. Paleoceanography 30, 2014PA002736. https://doi.org/10.1002/2014PA002736

Lee, S.-Y., Poulsen, C.J., 2008. Amplification of obliquity forcing through mean annual and seasonal atmospheric feedbacks. Clim Past 4, 205-213. https://doi.org/10.5194/cp-4-2052008

Leuschner, D.C., Sirocko, F., 2003. Orbital insolation forcing of the Indian Monsoon - a motor for global climate changes? Palaeogeogr. Palaeoclimatol. Palaeoecol., Indian Ocean Monsoons: Land and Sea Record 197, 83-95. https://doi.org/10.1016/S0031-0182(03)003870

Levy, R.H., Meyers, S.R., Naish, T.R., Golledge, N.R., McKay, R.M., Crampton, J.S., DeConto, R.M., Santis, L.D., Florindo, F., Gasson, E.G.W., Harwood, D.M., Luyendyk, B.P., Powell, R.D., Clowes, C., Kulhanek, D.K., 2019. Antarctic ice-sheet sensitivity to obliquity forcing enhanced through ocean connections. Nat. Geosci. 1. https://doi.org/10.1038/s41561018-0284-4

Lisiecki, L.E., Raymo, M.E., 2007. Plio-Pleistocene climate evolution: trends and transitions in glacial cycle dynamics. Quat. Sci. Rev. 26, 56-69.

https://doi.org/10.1016/j.quascirev.2006.09.005

Lisiecki, L.E., Raymo, M.E., 2005. A Pliocene-Pleistocene stack of 57 globally distributed benthic $\delta 180$ records. Paleoceanography 20, PA1003. https://doi.org/10.1029/2004PA001071

Liu, H.-S., 1999. Insolation changes caused by combination of amplitude and frequency modulation of the obliquity. J. Geophys. Res. Solid Earth 104, 25197-25206.

https://doi.org/10.1029/1999JB900246

Liu, H.-S., 1995. A new view on the driving mechanism of Milankovitch glaciation cycles. Earth Planet. Sci. Lett. 131, 17-26. https://doi.org/10.1016/0012-821X(95)00008-Z

Liu, H.-S., 1992. Frequency variations of the Earth's obliquity and the 100-kyr ice-age cycles. Nature 358, 397-399. https://doi.org/10.1038/358397a0

Liu, Y., Lo, L., Shi, Z., Wei, K.-Y., Chou, C.-J., Chen, Y.-C., Chuang, C.-K., Wu, C.-C., Mii, H.-S., Peng, Z., Amakawa, H., Burr, G.S., Lee, S.-Y., DeLong, K.L., Elderfield, H., Shen, C.C., 2015. Obliquity pacing of the western Pacific Intertropical Convergence Zone over the past 282,000 years. Nat. Commun. 6, 10018. https://doi.org/10.1038/ncomms10018 
Lourens, L., Hilgen, F., Shackleton, N.J., Laskar, J., Wilson, D., 2004. The Neogene Period, in: A Geologic Time Scale 2004. Cambridge University Press.

Lourens, L.J., Antonarakou, A., Hilgen, F.J., Van Hoof, A. a. M., Vergnaud-Grazzini, C., Zachariasse, W.J., 1996a. Evaluation of the Plio-Pleistocene astronomical timescale.

Paleoceanography 11, 391-413. https://doi.org/10.1029/96PA01125

Lourens, L.J., Becker, J., Bintanja, R., Hilgen, F.J., Tuenter, E., van de Wal, R.S.W., Ziegler, M., 2010. Linear and non-linear response of late Neogene glacial cycles to obliquity forcing and implications for the Milankovitch theory. Quat. Sci. Rev. 29, 352-365.

https://doi.org/10.1016/j.quascirev.2009.10.018

Lourens, L.J., Hilgen, F.J., 1997. Long-periodic variations in the earth's obliquity and their relation to third-order eustatic cycles and late Neogene glaciations. Quat. Int. 40, 43-52. https://doi.org/10.1016/S1040-6182(96)00060-2

Lourens, L.J., Hilgen, F.J., Raffi, I., Vergnaud $\square$ Grazzini, C., 1996b. Early Pleistocene chronology of the Vrica Section (Calabria, Italy). Paleoceanography 11, 797-812. https://doi.org/10.1029/96PA02691

Lourens, L.J., Wehausen, R., Brumsack, H.J., 2001. Geological constraints on tidal dissipation and dynamical ellipticity of the Earth over the past three million years. Nature 409, 1029-1033. https://doi.org/10.1038/35059062

Ma, C., Meyers, S.R., Sageman, B.B., 2017. Theory of chaotic orbital variations confirmed by Cretaceous geological evidence. Nature 542, 468-470. https://doi.org/10.1038/nature21402

Marković, S.B., Hambach, U., Stevens, T., Basarin, B., O’Hara-Dhand, K., Gavrilov, M.M., Gavrilov, M.B., Smalley, I., Teofanov, N., 2012. Relating the Astronomical Timescale to the Loess-Paleosol Sequences in Vojvodina, Northern Serbia, in: Berger, A., Mesinger, F., Sijacki, D. (Eds.), Climate Change. Springer Vienna, pp. 65-78.

Mélice, J.L., Coron, A., Berger, A., 2001. Amplitude and frequency modulations of the Earth's obliquity for the last million years. J. Clim. 14, 1043-1054. https://doi.org/10.1175/1520-0442(2001)014<1043:AAFMOT>2.0.CO;2

Melles, M., Brigham-Grette, J., Minyuk, P., Koeberl, C., Andreev, A., Cook, T., Fedorov, G., Gebhardt, C., Haltia-Hovi, E., Kukkonen, M., others, 2011. The Lake El'gygytgyn Scientific Drilling Project—conquering Arctic challenges through continental drilling. Sci. Drill. 11, 29-40.

Melles, M., Brigham-Grette, J., Minyuk, P.S., Nowaczyk, N.R., Wennrich, V., DeConto, R.M., Anderson, P.M., Andreev, A.A., Coletti, A., Cook, T.L., Haltia-Hovi, E., Kukkonen, M., Lozhkin, A.V., Rosén, P., Tarasov, P., Vogel, H., Wagner, B., 2012. 2.8 Million Years of Arctic Climate Change from Lake El'gygytgyn, NE Russia. Science 337, 315-320.

https://doi.org/10.1126/science.1222135 
Meyers, S.R., 2019. Cyclostratigraphy and the problem of astrochronologic testing. Earth-Sci. Rev. 190, 190-223. https://doi.org/10.1016/j.earscirev.2018.11.015

Meyers, S.R., 2015. The evaluation of eccentricity-related amplitude modulation and bundling in paleoclimate data: An inverse approach for astrochronologic testing and time scale optimization. Paleoceanography 30, 1625-1640. https://doi.org/10.1002/2015PA002850

Meyers, S.R., 2014. astrochron: An R Package for Astrochronology Version 0.8.

Meyers, S.R., 2012. Seeing red in cyclic stratigraphy: Spectral noise estimation for astrochronology. Paleoceanography 27, PA3228. https://doi.org/10.1029/2012PA002307

Meyers, S.R., Hinnov, L.A., 2010. Northern Hemisphere glaciation and the evolution of PlioPleistocene climate noise. Paleoceanography 25. https://doi.org/10.1029/2009PA001834

Meyers, S.R., Malinverno, A., 2018. Proterozoic Milankovitch cycles and the history of the solar system. Proc. Natl. Acad. Sci. 201717689. https://doi.org/10.1073/pnas.1717689115

Meyers, S.R., Sageman, B.B., 2007. Quantification of deep-time orbital forcing by average spectral misfit. Am. J. Sci. 307, 773-792. https://doi.org/10.2475/05.2007.01

Meyers, S.R., Sageman, B.B., Pagani, M., 2008. Resolving Milankovitch: Consideration of signal and noise. Am. J. Sci. 308, 770-786. https://doi.org/10.2475/06.2008.02

Meyers, S.R., Siewert, S.E., Singer, B.S., Sageman, B.B., Condon, D.J., Obradovich, J.D., Jicha, B.R., Sawyer, D.A., 2012. Intercalibration of radioisotopic and astrochronologic time scales for the Cenomanian-Turonian boundary interval, Western Interior Basin, USA.

Geology 40, 7-10. https://doi.org/10.1130/G32261.1

Mudelsee, M., Stattegger, K., 1997. Exploring the structure of the mid-Pleistocene revolution with advanced methods of time-series analysis. Geol. Rundsch. 86, 499-511.

https://doi.org/10.1007/s005310050157

Necula, C., Panaiotu, C., 2008. Application of dynamic programming to the dating of a loesspaleosol sequence. Romanian Rep. Phys. 60, 157-171.

Neeman, B.U., 1993. Orbital tuning of paleoclimatic records: a reassessment. Rep. No 39572 Lawrence Livermore Natl Lab.

Nowaczyk, N.R., Haltia, E.M., Ulbricht, D., Wennrich, V., Sauerbrey, M.A., Rosén, P., Vogel, H., Francke, A., Meyer-Jacob, C., Andreev, A.A., Lozhkin, A.V., 2013. Chronology of Lake El'gygytgyn sediments - a combined magnetostratigraphic, palaeoclimatic and orbital tuning study based on multi-parameter analyses. Clim Past 9, 2413-2432. https://doi.org/10.5194/cp-9-2413-2013

Pälike, H., Frazier, J., Zachos, J.C., 2006. Extended orbitally forced palaeoclimatic records from the equatorial Atlantic Ceara Rise. Quat. Sci. Rev. 25, 3138-3149. https://doi.org/10.1016/j.quascirev.2006.02.011 
Pälike, H., Laskar, J., Shackleton, N.J., 2004. Geologic constraints on the chaotic diffusion of the solar system. Geology 32, 929-932. https://doi.org/10.1130/G20750.1

Pälike, H., Shackleton, N.J., Röhl, U., 2001. Astronomical forcing in Late Eocene marine sediments. Earth Planet. Sci. Lett. 193, 589-602. https://doi.org/10.1016/S0012$821 \mathrm{X}(01) 00501-5$

Proistosescu, C., Huybers, P., Maloof, A.C., 2012. To tune or not to tune: Detecting orbital variability in Oligo-Miocene climate records. Earth Planet. Sci. Lett. 325-326, 100-107. https://doi.org/10.1016/j.eps1.2012.01.022

R Core Team, 2017. R: A Language and Environment for Statistical Computing.

Raymo, M.E., Nisancioglu, K.H., 2003. The 41 kyr world: Milankovitch's other unsolved mystery. Paleoceanography 18, 1011. https://doi.org/10.1029/2002PA000791

Raymo, M.E., Oppo, D.W., Flower, B.P., Hodell, D.A., McManus, J.F., Venz, K.A., Kleiven, K.F., McIntyre, K., 2004. Stability of North Atlantic water masses in face of pronounced climate variability during the Pleistocene. Paleoceanography 19, PA2008.

https://doi.org/10.1029/2003PA000921

Reichart, G.-J., 1997. Late quaternary variability of the Arabian Sea monsoon and oxygen minimum zone. Geol. Ultraiectina 154, 1-174.

Rial, J.A., 1999. Pacemaking the Ice Ages by Frequency Modulation of Earth's Orbital Eccentricity. Science 285, 564-568. https://doi.org/10.1126/science.285.5427.564

Ripepe, M., Fischer, A.G., 1991. Stratigraphic rhythms synthesized from orbital variations, in: Sedimentary Modeling. pp. 335-344.

Rivera, T.A., Storey, M., Zeeden, C., Hilgen, F.J., Kuiper, K., 2011. A refined astronomically calibrated 40Ar/39Ar age for Fish Canyon sanidine. Earth Planet. Sci. Lett. 311, 420-426. https://doi.org/10.1016/j.eps1.2011.09.017

Ruddiman, W.F., Raymo, M.E., Martinson, D.G., Clement, B.M., Backman, J., 1989. Pleistocene evolution: Northern hemisphere ice sheets and North Atlantic Ocean.

Paleoceanography 4, 353-412. https://doi.org/10.1029/PA004i004p00353

Sageman, B.B., Singer, B.S., Meyers, S.R., Siewert, S.E., Walaszczyk, I., Condon, D.J., Jicha, B.R., Obradovich, J.D., Sawyer, D.A., 2014. Integrating 40Ar/39Ar, U-Pb, and astronomical clocks in the Cretaceous Niobrara Formation, Western Interior Basin, USA. Geol. Soc. Am. Bull. B30929.1. https://doi.org/10.1130/B30929.1

Shackleton, N.J., Berger, A., Peltier, W.R., 1990. An alternative astronomical calibration of the lower Pleistocene timescale based on ODP Site 677. Earth Environ. Sci. Trans. R. Soc. Edinb. 81, 251-261. https://doi.org/10.1017/S0263593300020782

Shackleton, N.J., Crowhurst, S., 1997. Sediment fluxes based on an orbitally tuned time scale 5 Ma to 14 Ma, Site 926, in: Proc. ODP, Sci. Results. pp. 69-82. 
Shackleton, N.J., Hagelberg, T.K., Crowhurst, S.J., 1995. Evaluating the success of astronomical tuning: Pitfalls of using coherence as a criterion for assessing pre-Pleistocene timescales. Paleoceanography 10, 693-697. https://doi.org/10.1029/95PA01454

Spearman, C., 1904. The Proof and Measurement of Association between Two Things. Am. J. Psychol. 15, 72-101. https://doi.org/10.2307/1412159

Taner, M.T., 1992. in: Attributes revisted (Technical Report, Rock Solid Images, Inc), url: http://www.rocksolidimages.com/attributes-revisited/\#_Toc328470897.

Tiedemann, R., Sarnthein, M., Shackleton, N.J., 1994. Astronomic timescale for the Pliocene Atlantic $\delta 180$ and dust flux records of Ocean Drilling Program Site 659. Paleoceanography 9 , 619-638. https://doi.org/10.1029/94PA00208

Valero, L., Garcés, M., Cabrera, L., Costa, E., Sáez, A., 2014. 20 Myr of eccentricity paced lacustrine cycles in the Cenozoic Ebro Basin. Earth Planet. Sci. Lett. 408, 183-193. https://doi.org/10.1016/j.eps1.2014.10.007

von Suchodoletz, H., Oberhänsli, H., Hambach, U., Zöller, L., Fuchs, M., Faust, D., 2010. Soil moisture fluctuations recorded in Saharan dust deposits on Lanzarote (Canary Islands) over the last 180 ka. Quat. Sci. Rev. 29, 2173-2184.

https://doi.org/10.1016/j.quascirev.2010.05.014

Westerhold, T., Bickert, T., Röhl, U., 2005. Middle to late Miocene oxygen isotope stratigraphy of ODP site 1085 (SE Atlantic): new constrains on Miocene climate variability and sea-level fluctuations. Palaeogeogr. Palaeoclimatol. Palaeoecol. 217, 205-222. https://doi.org/10.1016/j.palaeo.2004.12.001

Westerhold, T., Röhl, U., 2009. High resolution cyclostratigraphy of the early Eocene - new insights into the origin of the Cenozoic cooling trend. Clim Past 5, 309-327.

https://doi.org/10.5194/cp-5-309-2009

Westerhold, T., Röhl, U., Laskar, J., 2012. Time scale controversy: Accurate orbital calibration of the early Paleogene. Geochem. Geophys. Geosystems 13, Q06015. https://doi.org/10.1029/2012GC004096

Westerhold, T., Röhl, U., Laskar, J., Raffi, I., Bowles, J., Lourens, L.J., Zachos, J.C., 2007. On the duration of magnetochrons C24r and C25n and the timing of early Eocene global warming events: Implications from the Ocean Drilling Program Leg 208 Walvis Ridge depth transect. Paleoceanography 22, PA2201. https://doi.org/10.1029/2006PA001322

Westerhold, T., Röhl, U., Pälike, H., Wilkens, R., Wilson, P.A., Acton, G., 2014. Orbitally tuned timescale and astronomical forcing in the middle Eocene to early Oligocene. Clim Past 10, 955-973. https://doi.org/10.5194/cp-10-955-2014

Westerhold, T., Röhl, U., Raffi, I., Fornaciari, E., Monechi, S., Reale, V., Bowles, J., Evans, H.F., 2008. Astronomical calibration of the Paleocene time. Palaeogeogr. Palaeoclimatol. Palaeoecol. 257, 377-403. https://doi.org/10.1016/j.palaeo.2007.09.016 
Wotzlaw, J.-F., Hüsing, S.K., Hilgen, F.J., Schaltegger, U., 2014. High-precision zircon U-Pb geochronology of astronomically dated volcanic ash beds from the Mediterranean Miocene.

Earth Planet. Sci. Lett. 407, 19-34. https://doi.org/10.1016/j.epsl.2014.09.025

Wu, H., Zhang, S., Hinnov, L.A., Jiang, G., Feng, Q., Li, H., Yang, T., 2013. Time-calibrated Milankovitch cycles for the late Permian. Nat. Commun. 4.

https://doi.org/10.1038/ncomms3452

Wu, H., Zhang, S., Hinnov, L.A., Jiang, G., Yang, T., Li, H., Wan, X., Wang, C., 2014. Cyclostratigraphy and orbital tuning of the terrestrial upper Santonian-Lower Danian in Songliao Basin, northeastern China. Earth Planet. Sci. Lett. 407, 82-95.

https://doi.org/10.1016/j.eps1.2014.09.038

Zech, W., Zech, R., Zech, M., Leiber, K., Dippold, M., Frechen, M., Bussert, R., Andreev, A., 2011. Obliquity forcing of Quaternary glaciation and environmental changes in NE Siberia. Quat. Int., Loess in Eurasia 234, 133-145. https://doi.org/10.1016/j.quaint.2010.04.016

Zeeden, C., Hilgen, F., Westerhold, T., Lourens, L., Röhl, U., Bickert, T., 2013. Revised Miocene splice, astronomical tuning and calcareous plankton biochronology of ODP Site 926 between 5 and 14.4 Ma. Palaeogeogr. Palaeoclimatol. Palaeoecol. 369, 430-451. https://doi.org/10.1016/j.palaeo.2012.11.009

Zeeden, C., Hilgen, F.J., Hüsing, S.K., Lourens, L.L., 2014a. The Miocene astronomical time scale 9-12 Ma: New constraints on tidal dissipation and their implications for paleoclimatic investigations. Paleoceanography 29, 2014PA002615. https://doi.org/10.1002/2014PA002615

Zeeden, C., Meyers, S.R., Lourens, L.J., Hilgen, F.J., 2015. Testing astronomically tuned age models. Paleoceanography 30, 2014PA002762. https://doi.org/10.1002/2014PA002762

Zeeden, C., Rivera, T.A., Storey, M., 2014b. An astronomical age for the Bishop Tuff and concordance with radioisotopic dates. Geophys. Res. Lett. 41, 2014 GL059899.

https://doi.org/10.1002/2014GL059899 

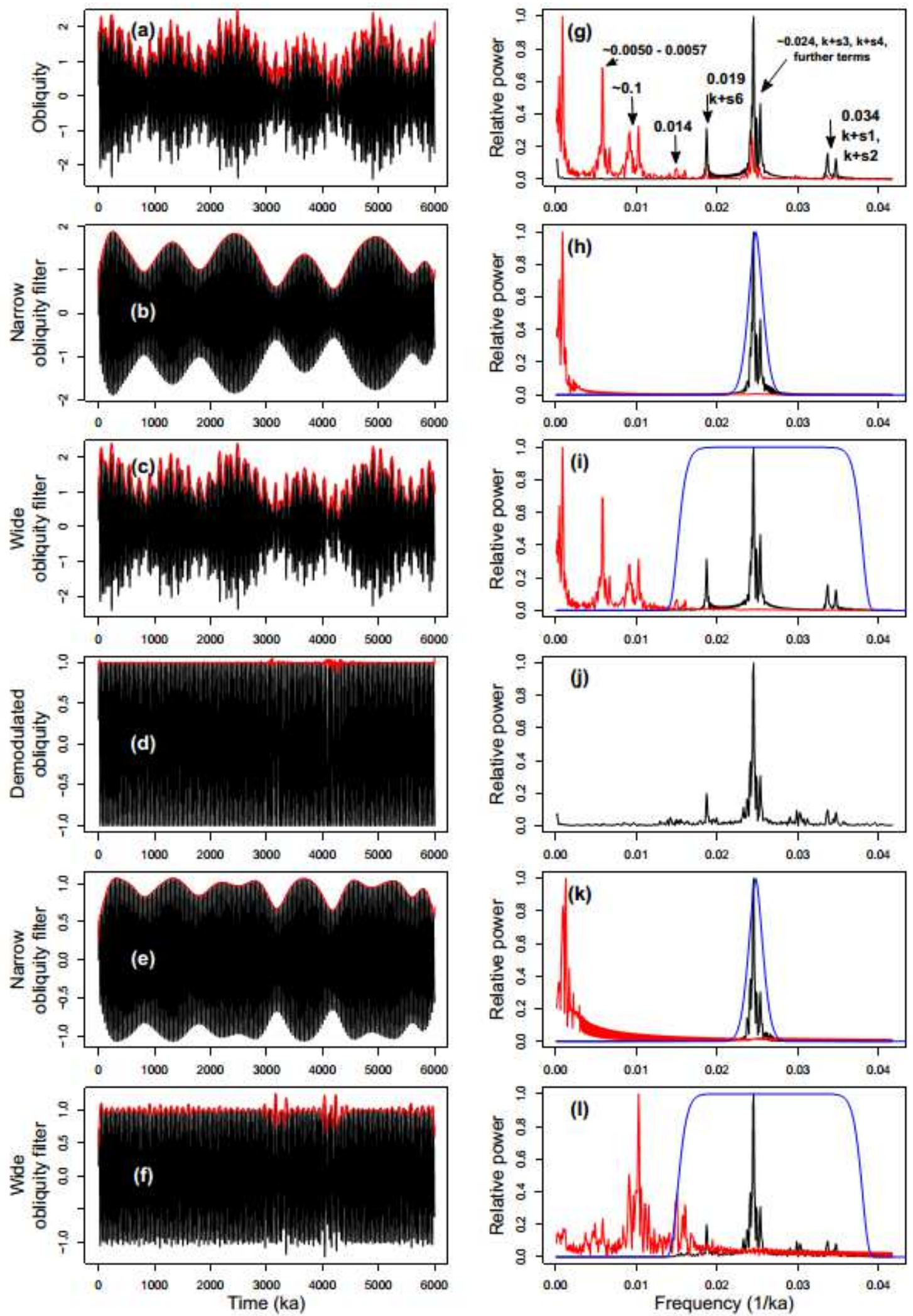

Figure 1: Analysis of the astronomical solution from Laskar et al. [2004], and the obliquity amplitude modulation, including (a) theoretical obliquity. Also shown are (b) output from a narrowband obliquity filter, (c) output from a wideband obliquity filter (d) a demodulated obliquity time series, note that the amplitude is very low, (e) output from a narrowband filter 
(filtering the demodulated signal), (f) output from a broadband filter (filtering the demodulated signal). The narrowband obliquity filter employs a Taner filter with cut off frequencies (half power points) at 0.0235 and 0.027 cycles/kyr, and a roll-off rate $10^{20}$. The broadband obliquity filter employs a Taner filter with cut off frequencies at 0.015 and 0.038 cycles/kyr, and a roll-off rate $10^{20}$. Instantaneous amplitude for each record, determined via Hilbert Transform, is shown in red. Panels (g-l) display power spectra (the squared modulus of the Fourier Transform) for each amplitude envelope (red), along with the spectra of the filtered series (black) and the Taner bandpass window used (blue lines).
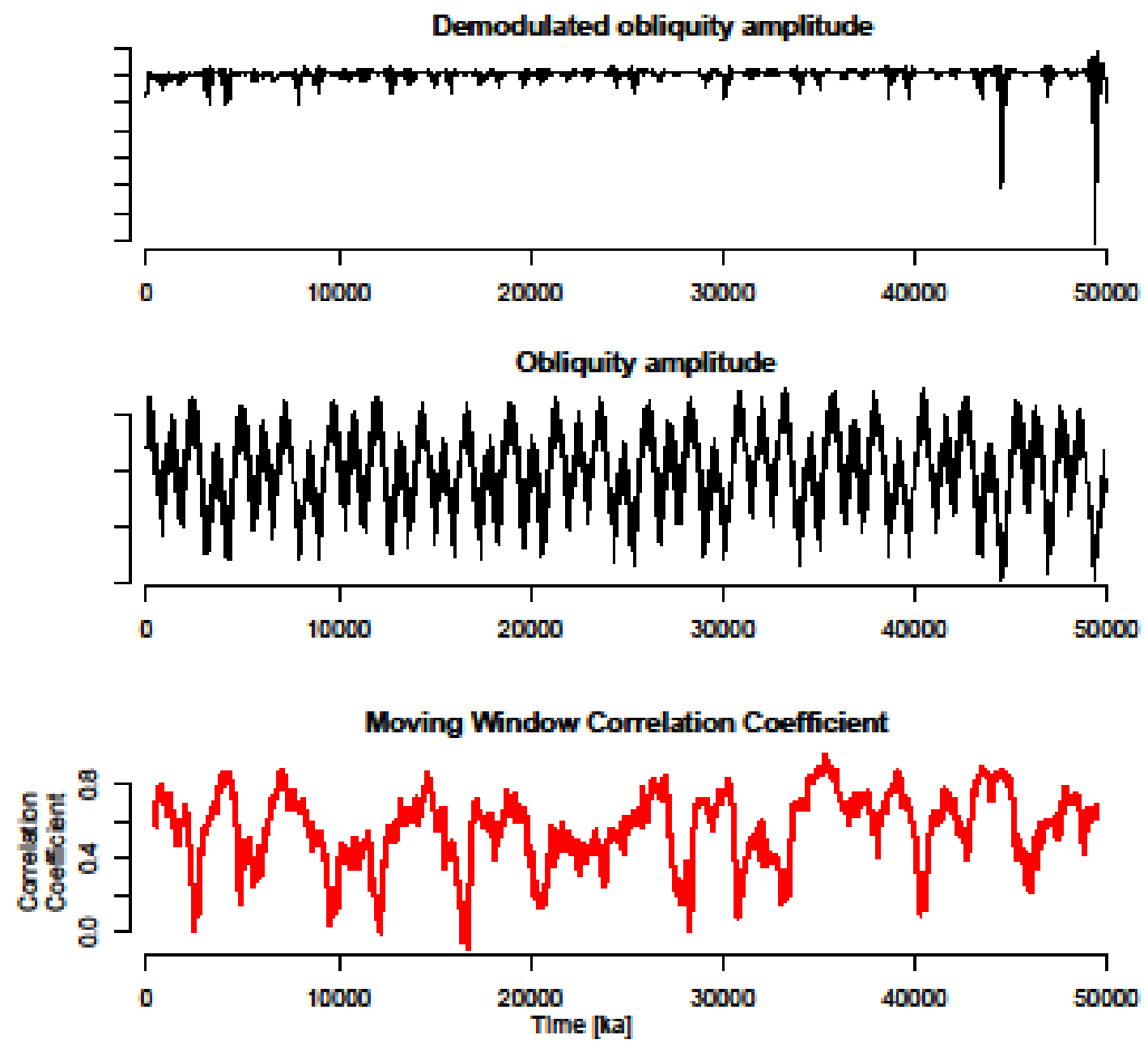

Figure 2: Frequency modulations of obliquity introduced by filtering over the last $50 \mathrm{Ma}$ $(50,000 \mathrm{ka})$. The top panel (a) shows the results of a wide band obliquity filter as in Fig. 11 applied to a demodulated obliquity series, the middle Panel (b) shows the same for (not demodulated) obliquity, and the bottom panel (c) shows the moving average Spearman Rank correlation using a $1000 \mathrm{ka}$ window. 

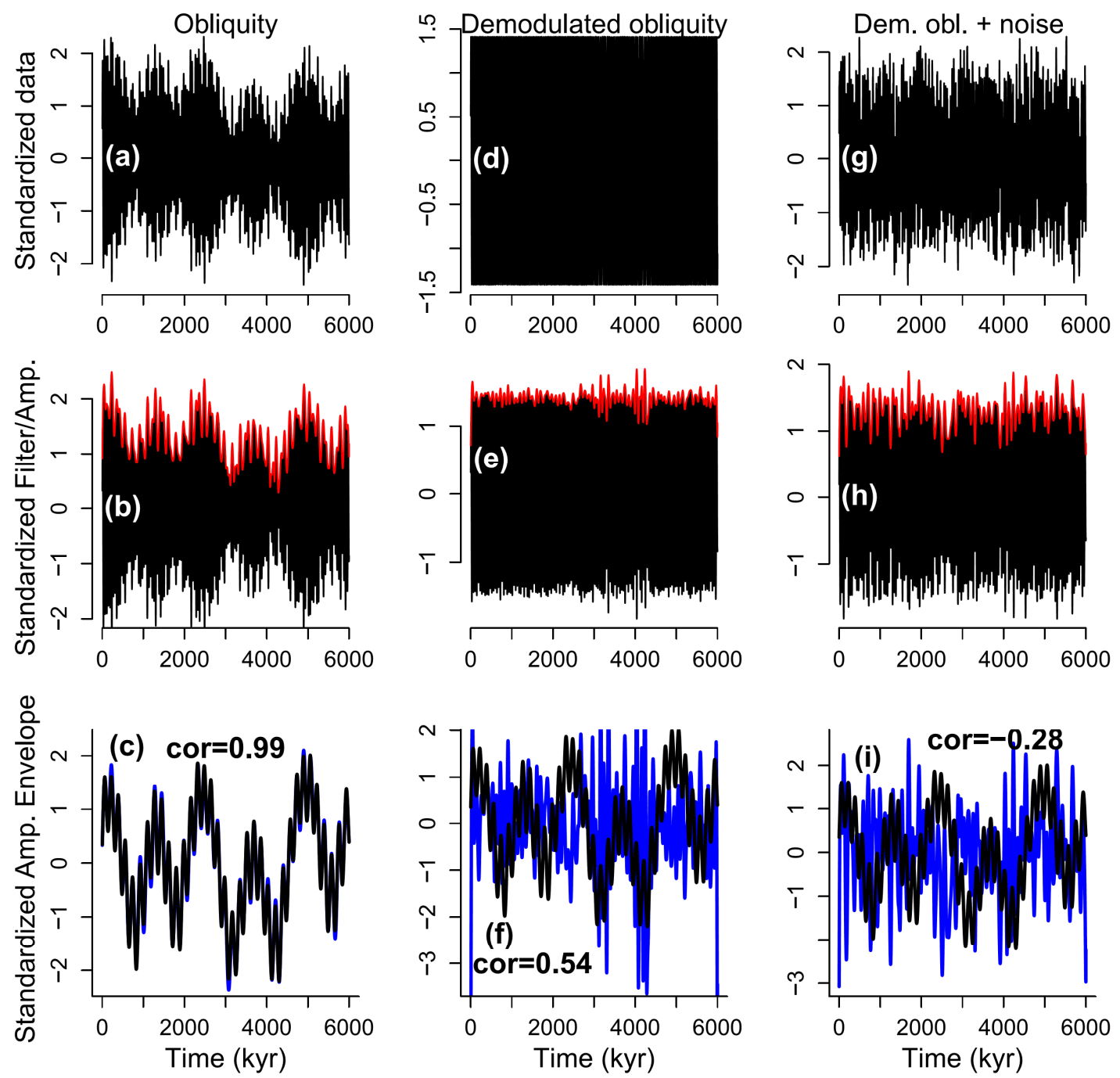

Figure 3: Demonstration of the complete algorithm as applied to a normalized obliquity series of the last $6 \mathrm{Ma}(\mathrm{a}-\mathrm{c})$, demodulated obliquity (d-f), and demodulated obliquity including $40 \%$ red noise (g-i). The first example (a-c) shows the extraction of obliquity, the second example (d-f) shows the persisting effect of frequency modulations even when using wideband filters and the third case (g-i) demonstrates the removal of this effect when incorporating noise. (a) Obliquity model series, (b) obliquity model filtered with a broadband obliquity filter (black), and its instantaneous amplitude (red). (c) Comparison of the final model (La2004) amplitude envelope (black) and the obliquity amplitude envelope (blue; processed using the same filtering algorithm). 

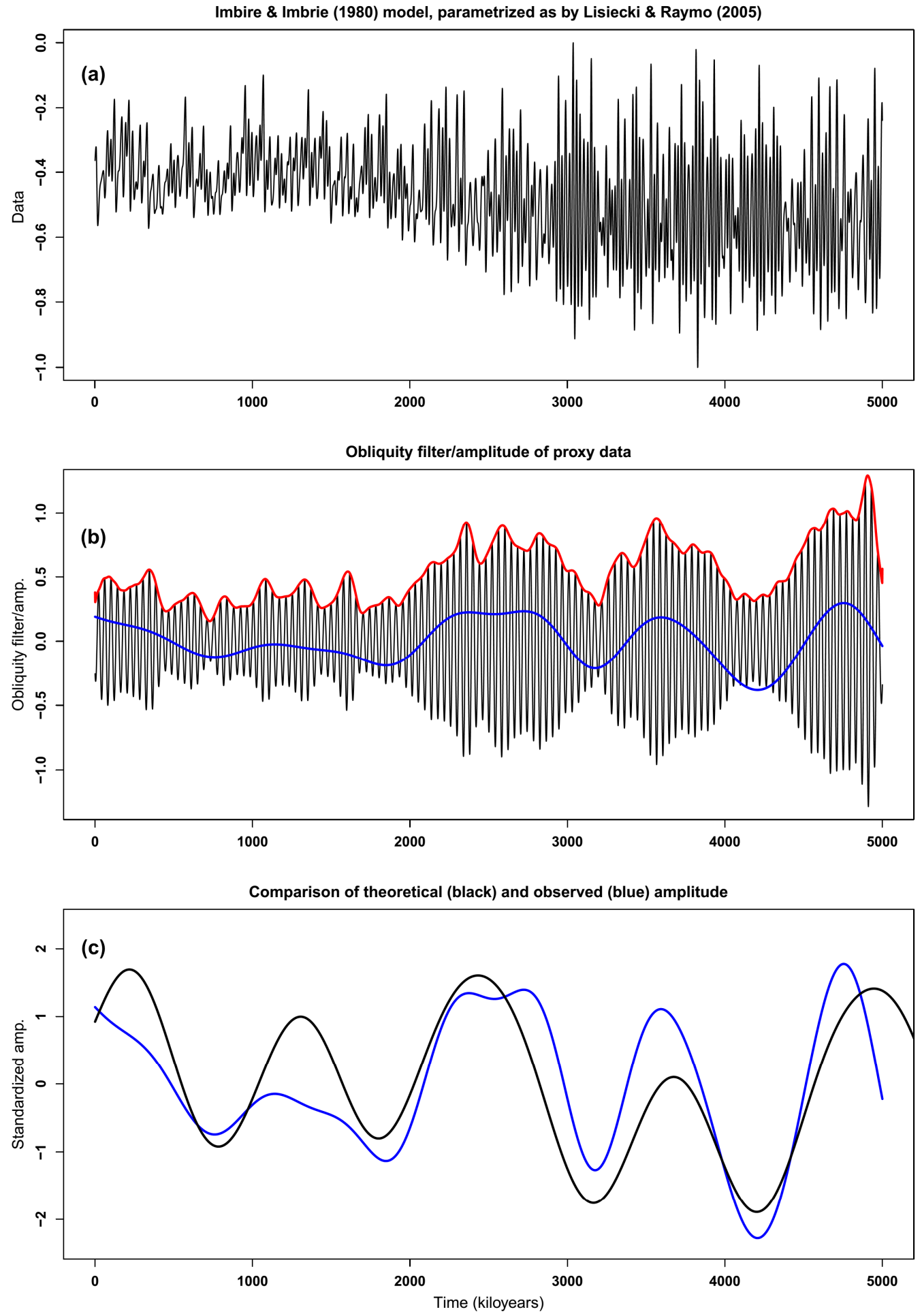

Figure 4: Evaluation of the (Imbrie and Imbrie, 1980) ice model. (a) Imbrie ice model series, (b) the model filtered with a broadband obliquity filter (black), its instantaneous amplitude (red), and the final amplitude envelope following application of a lowpass filter (blue), (c) comparison of the Imbrie ice model amplitude envelope (blue), and the amplitude envelope for theoretical obliquity (black; processed using the same filtering algorithm). For plotting purposes, all data series have been standardized (zero mean, unit standard deviation). 

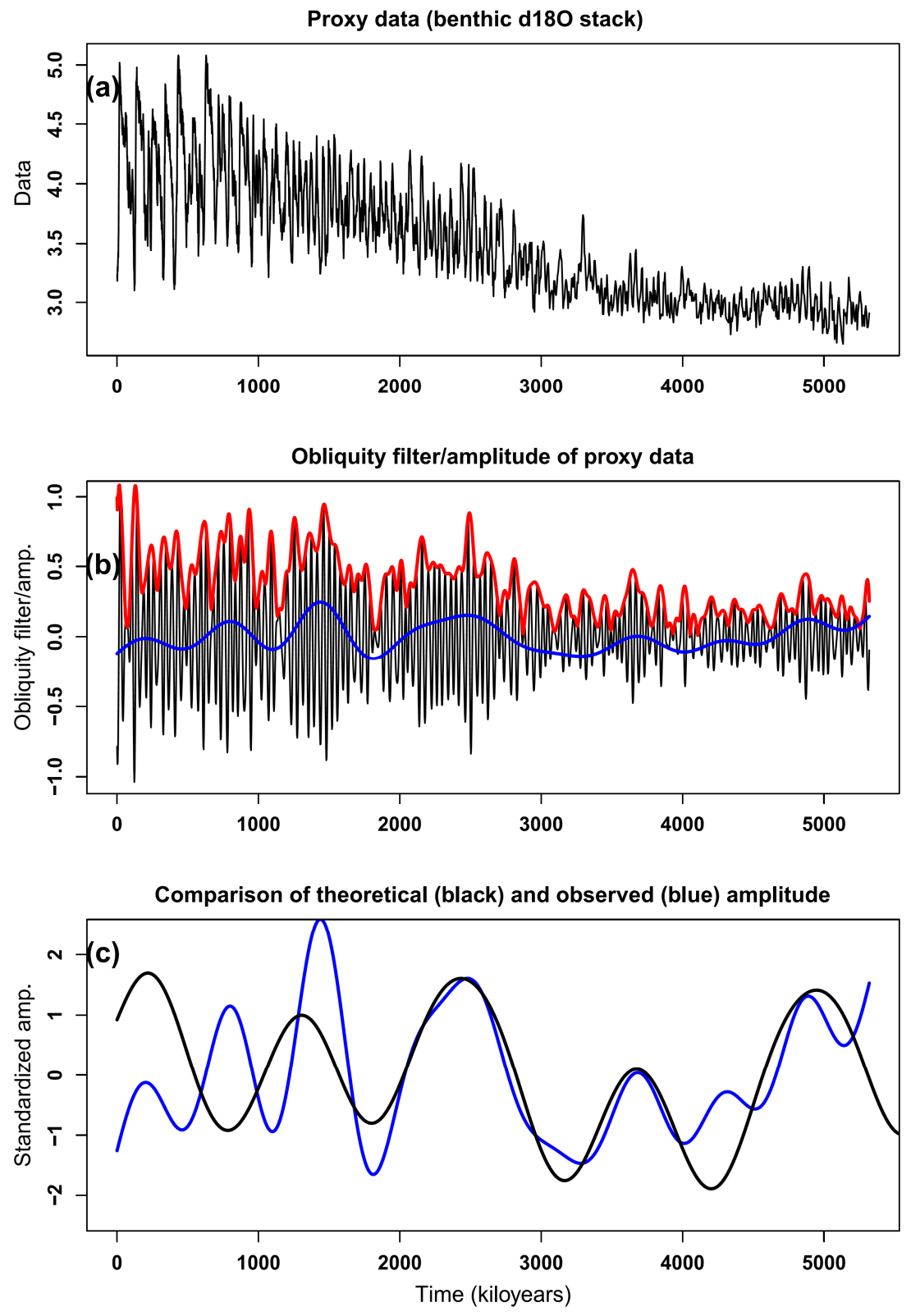

Figure 5: Evaluation of the LR04 benthic foraminifera oxygen isotope data (Lisiecki and Raymo, 2005). (a) Oxygen isotope data series, (b) data filtered with a broadband obliquity filter (black), its instantaneous amplitude (red), and the final amplitude envelope following application of a lowpass filter (blue), (c) comparison of the isotope data amplitude envelope (blue), and the amplitude envelope for theoretical obliquity (black; processed using the same filtering algorithm). For plotting purposes, all data series have been standardized (zero mean, unit standard deviation). 

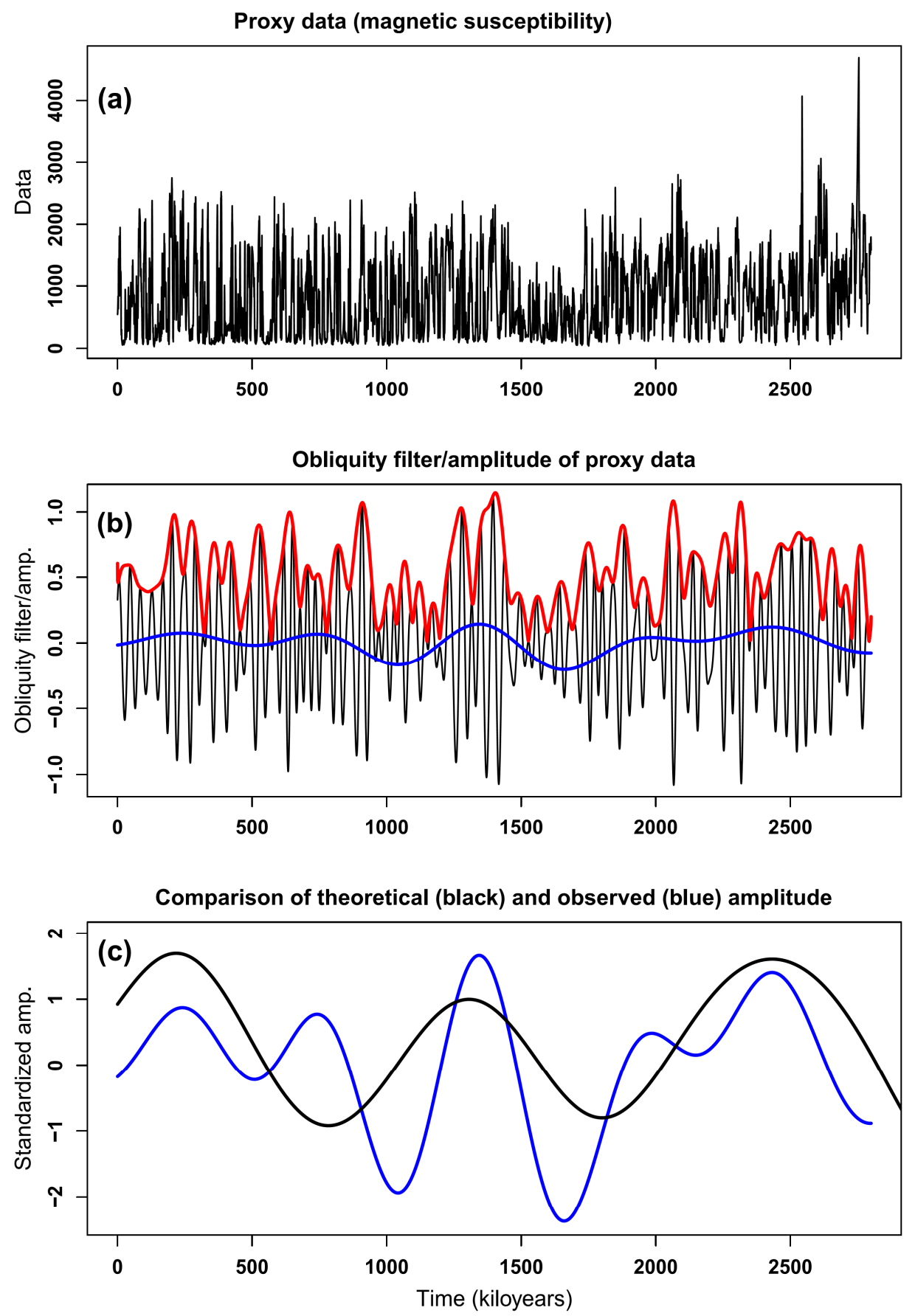

Figure 6: Evaluation of the Lake El'Gygytgyn magnetic susceptibility record. (a) The Lake El'Gygytgyn magnetic susceptibility record, (b) data filtered with a broadband obliquity filter (black), its instantaneous amplitude (red), and the final amplitude envelope following application of a lowpass filter (blue), (c) comparison of the amplitude envelope for the Lake El'Gygytgyn magnetic susceptibility data (blue) and the amplitude envelope for theoretical obliquity (black; processed using the same filtering algorithm). For plotting purposes, all data series have been standardized (zero mean, unit standard deviation). 

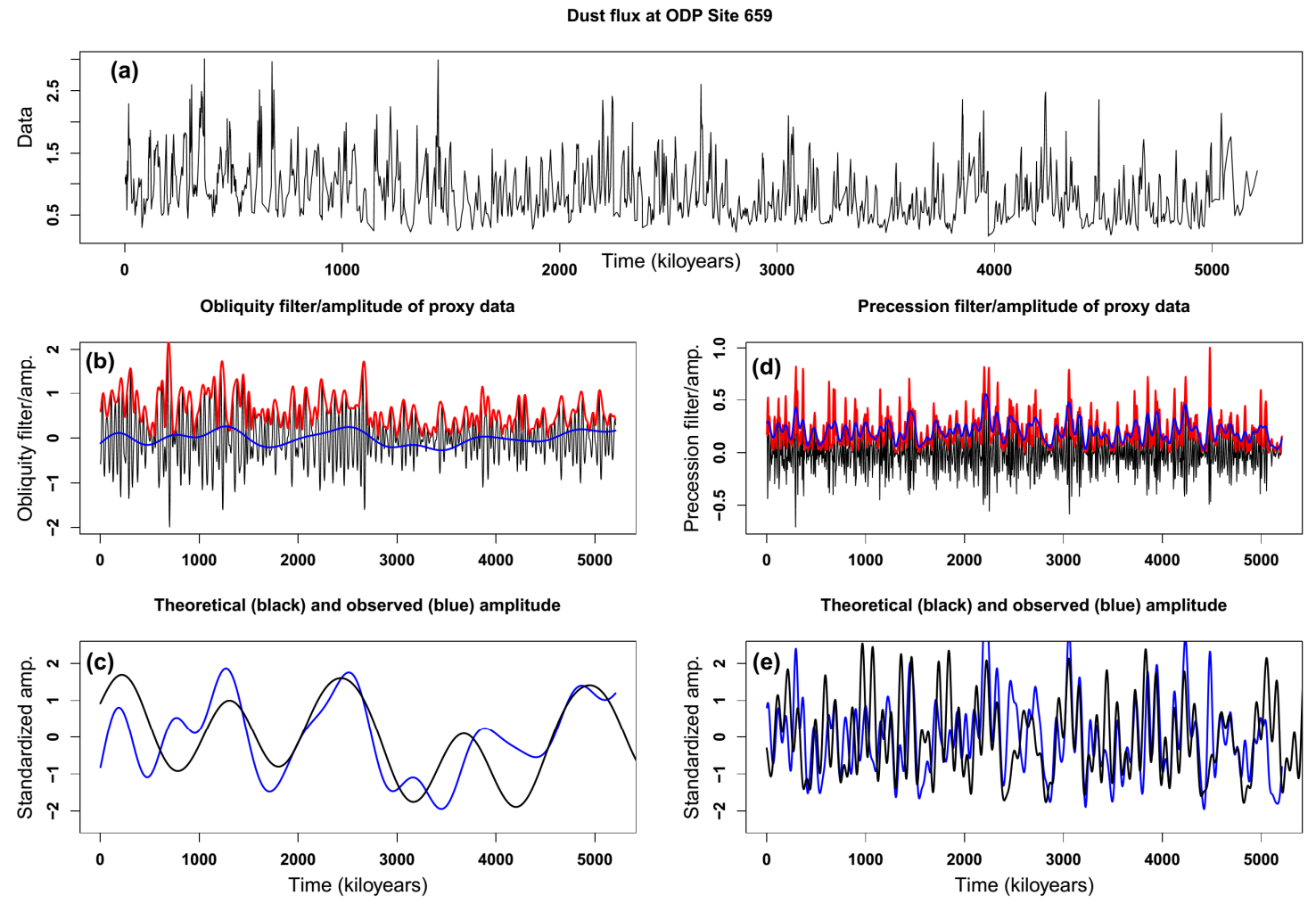

Figure 7: Evaluation of the ODP Site 659 dust record (Tiedemann et al., 1994) using both obliquity and precession amplitudes, for precession the 'testPrecession' method is used (Meyers, 2014; R Core Team, 2017; Zeeden et al., 2015). (a) Dust flux record, (b) data filtered with a broadband obliquity filter (black), its instantaneous amplitude (red), and the final amplitude envelope following application of a lowpass filter (blue), (c) comparison of the dust flux amplitude envelope (blue) and the amplitude envelope for theoretical obliquity (black; processed using the same filtering algorithm), (d) data filtered with a broadband precession filter (black), its instantaneous amplitude (red), and the final amplitude envelope following application of a lowpass filter (blue), and (e) comparison of the amplitude envelope (blue) and the amplitude envelope for theoretical precession (black; processed using the same filtering algorithm). For plotting purposes, all data series have been standardized (zero mean, unit standard deviation). 


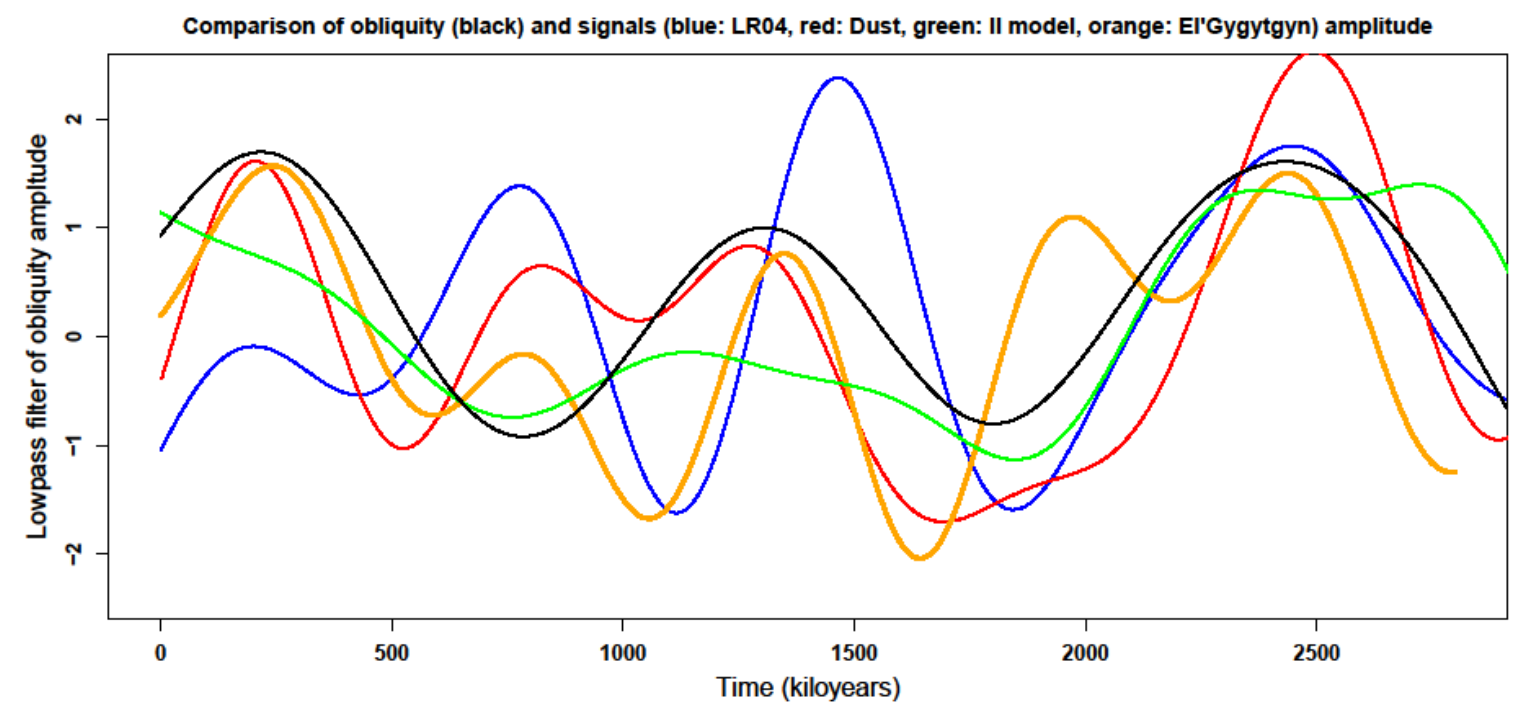

Figure 8: Comparison of theoretical obliquity amplitude (black), the three paleoclimate data sets investigated (blue: LR04, red: dust record from ODP Site 659, orange: Lake El'Gygytgyn), and the (Imbrie and Imbrie, 1980) ice model (green). Note that all datasets show higher than expected obliquity amplitude in the time interval from 700-900 ka, but this feature is not seen in the ice model nor the theoretical obliquity. 
3 Table 1: Properties of tested datasets. MS denotes magnetic susceptibility, ${ }^{*}$ denotes correlations (Spearman rank) between obliquity amplitudes. The 4 p-values, adjusted correlation and noise addition are not useful to determine for several datasets, because original correlation is negative. See the text 5 for interpretations.

\begin{tabular}{|c|c|c|c|c|c|c|c|c|}
\hline dataset & $\begin{array}{c}\text { (Investigated) } \\
\text { time span in ka }\end{array}$ & Figure & $\begin{array}{l}\text { average data } \\
\text { resolution [kyr] }\end{array}$ & $\begin{array}{c}\mathrm{AR}(1) \\
\text { correlation }\end{array}$ & $\begin{array}{c}\text { standardized } \\
\text { noise added }\end{array}$ & $\begin{array}{c}\text { original } \\
\text { correlation* }\end{array}$ & $\begin{array}{c}\text { adjusted } \\
\text { correlation* }\end{array}$ & p-value \\
\hline Obliquity & $0-6000$ & 3 & 1 & 0.988 & 0.376 & 1 & 0.99 & $<0.01$ \\
\hline demodulated Obliquity & $0-6000$ & 3 & 1 & 0.988 & 0.291 & 0.54 & -0041 & - \\
\hline demodulated Obliquity + noise & $0-6000$ & 3 & 1 & 0.976 & 0.239 & -0.06 & -0.28 & - \\
\hline LR04 benthic isotope stack & $0-5000$ & 5,8 & 2.5 & 0.975 & 0.112 & 0.638 & 0.632 & 0.0145 \\
\hline Imbrie \& Imbrie 1980 ice model & $0-5000$ & 4,8 & 1 & 0.975 & 0.071 & 0.884 & 0.886 & $<0.001$ \\
\hline Lake El'Gygytgyn MS & $0-2800$ & 6,8 & 0.5 & 0.911 & 0.004 & 0.652 & $0.655 \mathrm{~s}$ & 0.0490 \\
\hline ODP Site 659 dust flux & $0-5208$ & 7,8 & 3.7 & 0.969 & 0.080 & 0.610 & 0.593 & 0.0135 \\
\hline
\end{tabular}

